\title{
Pemberdayaan Masyarakat Melalui Penerapan Teknik Integrasi Tanaman-Ternak Berbazis Zero Waste Agriculture
}

\author{
Nur Hayati', Sitti Rahmawati², Usman Made ${ }^{3}$, Haerani Maksum ${ }^{4}$, Sri Anjar Lasmini5 ${ }^{5}$, Rosmini6 \\ 1,3,5,6,Program Studi Agroteknologi Fakultas Pertanian Universitas Tadulako \\ ${ }^{2}$ Program Studi Pendidikan Kimia Fakultas Keguruan dan Ilmu Pendidikan Universitas Tadulako \\ ${ }^{4}$ Program Studi Peternakan Fakultas Peternakan dan Perikanan Universitas Tadulako \\ *e-mail: nurhayatirs939@gmail.com
}

\begin{abstract}
The potential of agricultural and livestock resources in Pombewe Village is quite available but not yet optimally utilized by the community. Agricultural land is still largely abandoned and livestock are still left to graze themselves. The problem faced by the community is the lack of skills on how to improve agricultural products. This community empowerment program aims to assist the community in applying the integration of zero waste agriculture techniques. The method applied is community development with activities in the form of counseling, training, demonstration plots and mentoring with output targets is to increase the community's insight, knowledge and skills. The results achieved were an increase in community knowledge and skills characterized by the ability of the community to use agricultural and livestock waste to be economically valuable by making liquid organic fertilizer, compost, and can cultivate forage grass as animal feed.
\end{abstract}

Keywords: agriculture; animal husbandry; liquid fertilizer, local microorganisms, waste

\begin{abstract}
Abstrak
Potensi sumberdaya pertanian dan peternakan di Desa Pombewe cukup tersedia tetapi belum dimanfaatkan secara optimal oleh masyarakat. Lahan pertanian masih banyak diterlantarkan dan ternak dibiarkan merumput sendiri. Permasalahan yang dihadapi oleh masyarakat yaitu kurangnya ketrampilan tentang tatacara peningkatan produk hasil pertanian. Atas permasalahan tersebut, dilakukan pendampingan masyarakat untuk mengembangkan Desa Pombewe menjadi Desa Mandiri Pangan berbasis usahatani terintegrasi tanaman dan ternak. Program pemberdayaan masyarakat ini bertujuan untuk mendampingi masyarakat dalam menerapkan teknik integrasi tanaman dan ternak berbazis zero waste agriculture. Metode yang diterapkan adalah community development dengan kegiatan berupa penyuluhan, pelatihan, demplot percontohan dan pendampingan dengan target luaran adalah peningkatan wawasan, pengetahuan serta ketrampilan masyarakat. Hasil yang dicapai adalah peningkatan pengetahuan dan ketrampilan masyarakat yang ditandai dengan kemampuan memanfaatkan limbah pertanian dan peternakan menjadi bernilai secara ekonomi yakni dengan membuat pupuk organik cair MOL, pupuk kompos, dan melakukan budidaya rumput hijauan sebagai pakan ternak.
\end{abstract}

Kata kunci: limbah; peternakan; pertanian; pupuk cair, mikroorganisme lokal

\section{PENDAHULUAN}

Desa Pombewe Kecamatan Sigi Biromaru merupakan salah satu sentra pertanian tanaman pangan dan juga sebagai salah satu desa dengan jumlah ternak terbanyak di Kecamatan Sigi Biromaru. Desa Pombewe memiliki luas wilayah sebesar $57,39 \mathrm{~km}^{2}$ dengan batas-batas administratif sebagai berikut: Sebelah barat dengan Desa Jono Oge, sebelah timur dengan Sungai Tanggowuno, dan sebelah selatan dengan Desa Sidera, sebelah utara dengan Desa Loru. Masyarakat Desa Pombewe umumnya bekerja sebagai petani dengan luas sawah yang ada mencapai 1.212 ha dan sebagian besar dimanfaatkan sebagai pengembangan pangan dan palawija diantaranya jenis tanaman padi dan tanaman jagung. Selain itu masyarakat juga memiliki ternak sapi dan kambing. Jumlah ternak sapi tercatat sebanyak 690 ekor dan ternak kambing sebanyak 428 ekor (BPS Kabupaten Sigi, 2016).

Memperhatikan potensi sumberdaya pertanian dan peternakan yang ada memberikan gambaran bahwa di desa tersebut cukup tersedia sumberdaya untuk kelangsungan hidup dan kemakmuran masyarakatnya. Akan tetapi sampai saat ini masih banyak masyarakat yang tergolong sebagai masyarakat pra-sejahtera. Hal tersebut karena masyarakat kurang memiliki pengetahuan dan ketrampilan dalam memanfaatkan potensi yang dimiliki terutama potensi 
sumberdaya pertanian dan peternakan. Lahan pertanian banyak yang masih diterlantarkan karena kurangnya teknologi pertanian yang diketahui oleh masyarakat. Demikian juga ternak hanya dibiarkan merumput sendiri tanpa diberi pakan yang memadai agar dapat berkembang dengan baik. Praktek budidaya yang dilakukan oleh masyarakat bersifat konvensional dengan kegiatan usaha tani dikerjakan secara parsial, belum dilakukan dengan pendekatan integral. Pertanian konvensional pada tahap-tahap awal mampu meningkatkan produktivitas pertanian secara nyata, tetapi dalam jangka panjang, efisiensi produksi semakin menurun karena berbagai efek samping yang merugikan seperti penurunan kesuburan tanah dan kehilangan bahan organik tanah.

Atas berbagai masalah tersebut di atas maka Program pengembangan desa mitra (PPDM) melakukan pembinaan kepada masyarakat untuk memanfaatkan potensi sumberdaya dengan pendekatan sistem pengelolaan pertanian terpadu yaitu suatu sistem usaha tani yang mengintegrasikan tanaman dan ternak. Dengan sistem usaha tani terpadu dapat menunjang ketersediaan pupuk organik bagi petani karena limbah peternakan dimanfaatkan menjadi pupuk dan limbah pertanian dapat menjadi pakan ternak. Model usaha tani seperti tersebut lebih dikenal dengan konsep zero waste agriculture. Integrasi antara tanaman dan ternak dapat meningkatkan keuntungan dari segi ekonomi selain itu dapat memperbaiki kondisi kesuburan tanah.

Program pengembangan desa mitra bertujuan untuk memberdayakan masyarakat melalui penerapan usaha tani terintegrasi tanaman dan ternak berbazis zero waste agriculture agar pendapatan masyarakat meningkat sekaligus mempertahankan dan meningkatkan kualitas lingkungan dan melestarikannya.

\section{METODE}

\section{Waktu dan Tempat}

PPDM dilaksanakan pada bulan April sampai dengan Juli 2020 dengan mitra kegiatan adalah anggota kelompok tani ternak "Singgani" Desa Pombewe Kecamatan Sigi Biromaru Kabupaten Sigi.

\section{Metode Pendekatan}

Program pengabdian masyarakat ini menggunakan teknik pengembangan masyarakat (community development) yang menekankan pembelajaran orang dewasa. Bentuk kegiatan yang dilakukan adalah:

1) Ceramah/diskusi, dinilai lebih efektif memberikan pengetahuan dasar tentang manajemen pemeliharaan, produksi, pengolahan dan pemasaran yang efektif dan efisien dengan didukung oleh modul-modul praktis

2) Penyuluhan dan Pelatihan, bertujuan untuk meningkatkan ketrampilan masyarkat dalam aplikasi inovasi seperti pelatihan pengoperasian alat, formulasi pakan, pengomposan, pembuatan biopestisida, produksi aneka olahan dari sayuran, dan pembukuan.

3) Pembuatan demo ploting yaitu praktek aplikasi teknologi di lapangan agar masyarakat bisa melihat secara langsung terapannya dalam kehidupan nyata, seperti demo ploting pertanian organik, aplikasi formula pakan komplit, sistem integrasi pertanian dan peternakan.

4) Pendampingan, yaitu pembinaan secara berkala dan berkelanjutan mengenai adopsi/aplikasi teknologi dalam praktek langsung pada tingkat masyarakat. Metode ini dilaksanakan setelah tiga metode di atas telah dilalui dan kelompok mitra telah diyakini memahami materi yang diberikan, selanjutnya dilakukan pemantapan dengan pendampingan secara berkelanjutan. Pendampingan diharapkan dapat memperbaiki sikap, perilaku, keterampilan dan kesadaran kelompok mitra dalam mengelola agribisnisnya dengan tetap memperhatikan kelangsungan ekosistem dalam rangka mewujudkan pembangunan pertanian yang menguntungkan dan berwawasan lingkungan (Kartasapoetra, 1994). 


\section{Konsep Penyelesaian Masalah}

Untuk menyelesaikan masalah yang dihadapi oleh kelompok masyarakat, dilakukan dengan pendekatan pengelolaan tanaman dan ternak secara terintegrasi. Dalam pelaksanaan PPDM ini, kelompok masyarakat yang menjadi menjadi mitra dilatih dan didampingi dalam penerapan pengelolaan tanaman dan ternak secara terintegrasi (terpadu) dan berkelanjutan sehingga teknologi tersebut diharapkan dapat menjadi mapan di masyarakat.

Konsep penyelesaian masalah dilakukan melalui pendekatan zero waste agriculture yakni dengan prinsip pengelolaan sumberdaya untuk menghasilkan kebutuhan pokok manusia sekaligus mempertahankan dan meningkatkan kualitas lingkungan dan melestarikannya. Hal tersebut dapat dilakukan dengan mengoptimalkan pemanfaatan sumber daya alam dan manusia setempat, misalnya pemanfaatan limbah pertanian sebagai pakan ternak, bahan pestisida dan pupuk organik serta penggunaannya sebagai bahan bangunan.

Zero waste agriculture berorientasi pada siklus penguraian makhluk hidup yaitu memanfaatkan limbah pertanian menjadi agen pupuk hijau, pestisida organik atau pakan ternak serta mengurangi/meninggalkan penggunaan senyawa kimia dalam mengolah lahan pertanian. limbah pertanian dapat digunakan sebagai ransum pakan ternak dan disisi lain, hewan ternak menghasilkan kotoran yang dapat dikelola menjadi pupuk organik yang dapat menyuburkan tanaman (Salikin, 2003).

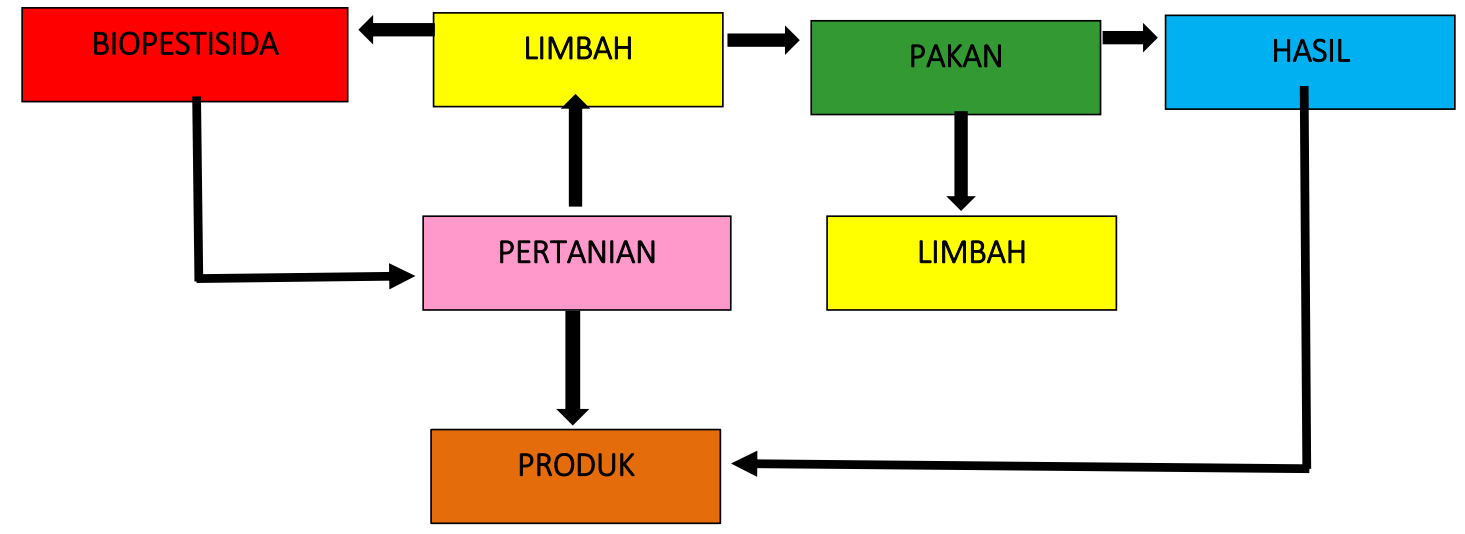

Gambar 1. Siklus Model pertanian Zero Waste Agriculture

Model zero waste agriculture tidak hanya berorientasi pada peningkatan produksi tani dengan mengadopsi sistem integrasi pertanian terpadu, tetapi juga melakukan rehabilitasi pada lahan kritis unsur hara sehingga dapat digunakan sebagai lahan pertanian produktif. Model zero waste agriculture memiliki empat prinsip utama yaitu, ramah lingkungan, rehabilitasi lahan, sistem berkelanjutan, dan pangan sehat (Sabiham, 2008).

Dengan pendampingan kepada kelompok masyarakat dalam penerapan sistem zero waste agriculture diharapkan dapat menjadi alternatif dalam pengelolaan lahan pertanian sehingga masa tanam lahan dapat berkelanjutan dan swasembada pangan berkelanjutan dapat terwujud.

\section{HASIL DAN PEMBAHASAN}

\section{Penyuluhan dan Pelatihan}

Penyuluhan dan pelatihan yang dilaksanakan meliputi pengembangan pupuk organik cair mikroorganisma lokal (MOL) yang memanfaatkan limbah organik rumah tangga, pengembangan kompos, pengembangan pestisida rasional, dan pengembangan pakan ternak. Kegiatan 
penyuluhan dilakukan dengan metode ceramah yang dilanjutkan dengan diskusi agar permasalahan yang dihadapi oleh peserta diberikan solusi, sebagaimana tujuan dari penyuluhan adalah meningkatkan pengetahuan peserta dan tujuan pelatihan adalah meningkatkan keterampilan dan mempengaruhi sikap serta motivasi untuk berpartisipasi dalam kegiatan kelompok tani (Kartasapoetra, 1994).

Sistem yang digunakan dalam pelaksanaan penyuluhan adalah klasikal yang bersifat teori atau kajian. Pada saat penyuluhan dan pelatihan juga dirangkaikan penyerahan bantuan bahan peralatan secara simbolis yang digunakan selama pelatihan kepada ketua kelompok tani mitra. Suasana penyuluhan dan penyerahan bahan dan peralatan ditunjukkan pada Gambar 2.
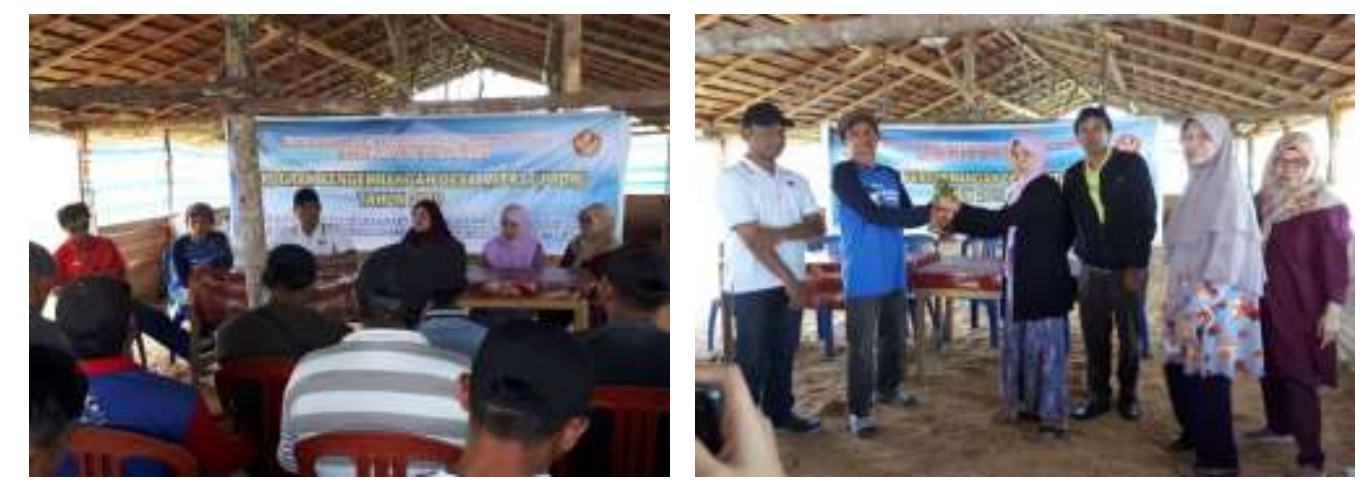

Gambar 2. Dokumentasi saat penyuluhan (a) dan penyerahan bantuan bahan dan peralatan (b)

\section{Pelatihan pengembangan pupuk cair berbahan mikroorganisma lokal (MOL) sayuran dan buah}

Larutan MOL mengandung unsur mikro dan makro dan juga mengandung bakteri yang berpotensi sebagai perombak bahan organik, perangsang tumbuhan, dan sebagai agens pengendali hama dan penyakit tanaman, sehingga MOL dapat digunakan baik sebagai dekomposer pupuk hayati dan sebagai pestisida organik, terutama sebagai fungisida. Sisa sayuran dan buah-buahan yang sudah tidak dimakan dapat dimanfaatkan sebagai MOL. Dengan memanfaatkan limbah rumah tangga menjadi MOL maka persoalan sampah rumah tangga dapat teratasi (Nalhadi $d k k ., 2020$ ).

Pelatihan pembuatan MOL sayuran dan buah dilaksanakan di halaman rumah salah seorang peserta (Gambar 2). Metode pembuatan MOL sayuran dan buah mengacu pada (Nurazizah, 2019), yang dimodifikasi yaitu dimulai dengan mengumpulkan bahan sayuran dan buah-buahan yang dijadikan MOL. Selanjutnya bahan sayuran dan buah-buahan tersebut dicacah sebanyak $10 \mathrm{~kg}$ kemudian diblender dan diperas lalu air perasan dimasukkan ke dalam wadah gallon. Selanjutnya ditambahkan gula pasir sebanyak $500 \mathrm{~g}$, air kelapa 5 l, EM4 $100 \mathrm{ml}$, dan air cucian beras 1 liter. Volume semua larutan tersebut berkisar 15 liter. Setelah larutan tersebut dimasukkan ke dalam gallon, kemudian gallon ditutup dan bagian tengah dilubangi dengan diamater $1 \mathrm{~cm}$ lalu dihubungkan dengan selang plastik bening ke dalam wadah gallon. Larutan MOL yang telah dibuat selanjutnya difermentasikan selama 14 hari, dan pupuk MOL buah-buahan siap diaplikasikan. 

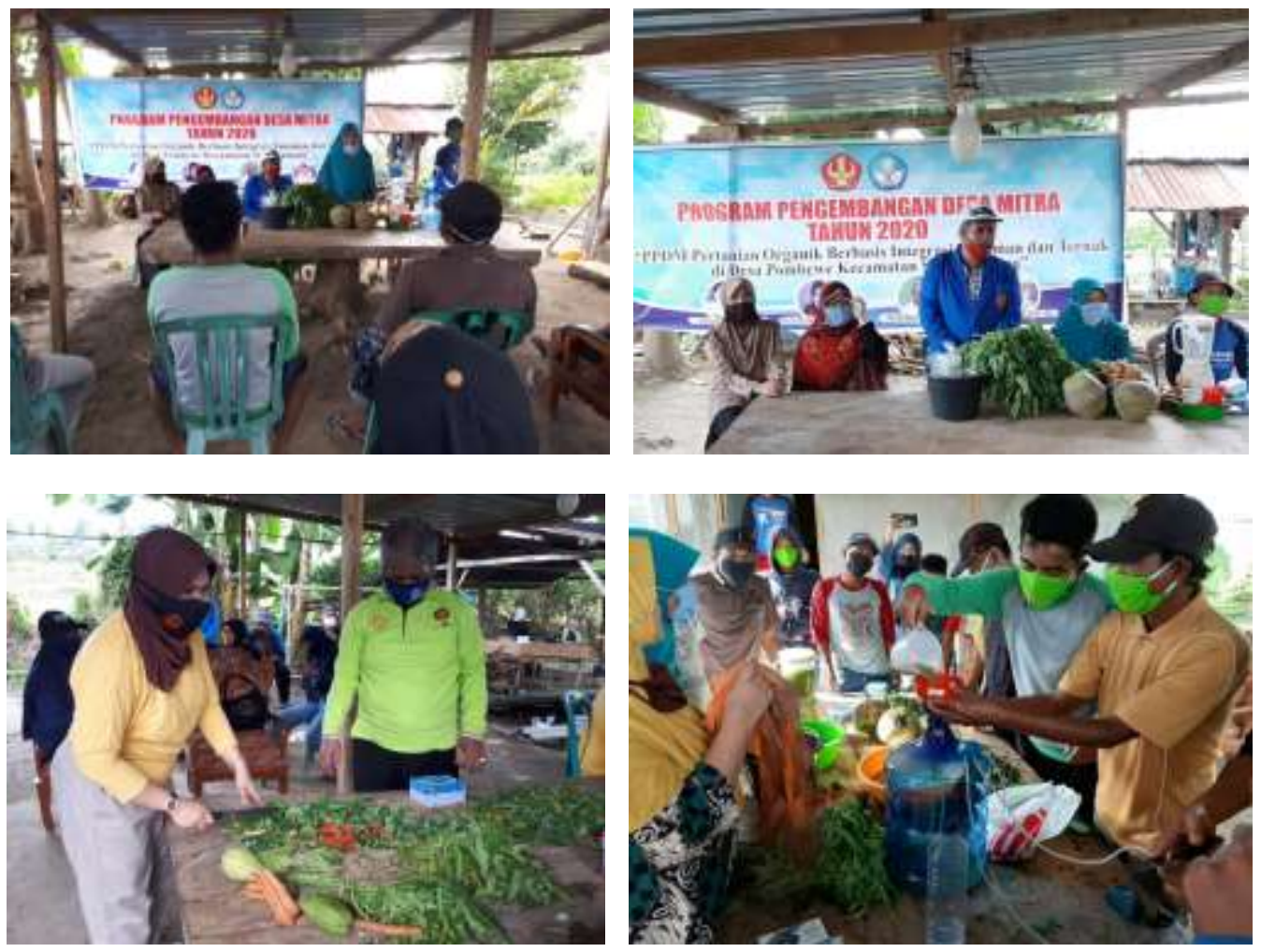

Gambar 2. Dokumentasi pelatihan pembuatan pupuk organik cair MOL sayuran dan buah

Aplikasi MOL buah sebagai biang kompos dilakukan dengan mencampur $1 \mathrm{l}$ MOL dengan $5 \mathrm{l}$ air dan ditambahkan dengan gula pasir sebanyak 1 ons kemudian disemprotkan ke campuran bahan organik, sedangkan MOL buah sebagai pupuk dilakukan dengan mengencerkan $1 \mathrm{l} \mathrm{MOL}$ dengan $15 \mathrm{l}$ air kemudian disemprotkan ke tanaman (Kurniawati, 2018). MOL buah sebagai biang kompos (bioaktivator) mengandung bakteri Clavibacter, Agrobacterium, Clostridium, Pseudomonas berfluorescens sehingga mampu mempercepat proses pengomposan yakni menjadi 10 hari (Manullang \& Daryono, 2017), dan karena mengandung berbagai jenis mikroorganisme bermanfaat maka pupuk cair MOL dapat digolongkan sebagai pupuk hayati (Bande $d k k$., 2020).

\section{Pelatihan pengembangan pupuk kompos}

Metode 'heap' diterapkan dalam pembuatan kompos (Setyorini $d k k$., 2007). Pelatihan pengembangan kompos diawali dengan pembuatan bak pengomposan (rumah kompos) yang berukuran 4 × 2 m dengan dinding yang terbuat dari papan. Selanjutnya material/bahan kompos berupa kotoran ternak sapi, jerami dan sekam padi serta daun-daun hijauan segar yang dipotongpotong kecil, kemudian dimasukkan ke dalam bak pengomposan sampai penuh. Setelah material tersebut dimasukkan ke dalam bak pengomposan, dilakukan proses fermentasi menggunakan EM4 yang sudah diencerkan dengan air dan ditambahkan dengan molases. Proses selanjutnya adalah dengan menyiramkan larutan EM-4 tersebut ke material kompos dan selanjutnya diaduk merata dan disiramkan dengan air sampai menjadi adonan. Setelah proses fermentasi dianggap selesai, bahan kompos tersebut ditutup dengan karung. Kompos yang sudah matang dicirikan dengan warna sudah menyerupai tanah yaitu warna kehitam-hitaman dan aromanya seperti aroma humus (Haq $d k k$., 2014). Rangkaian pelaksanaan pembuatan kompos ditunjukkan pada Gambar 3. 


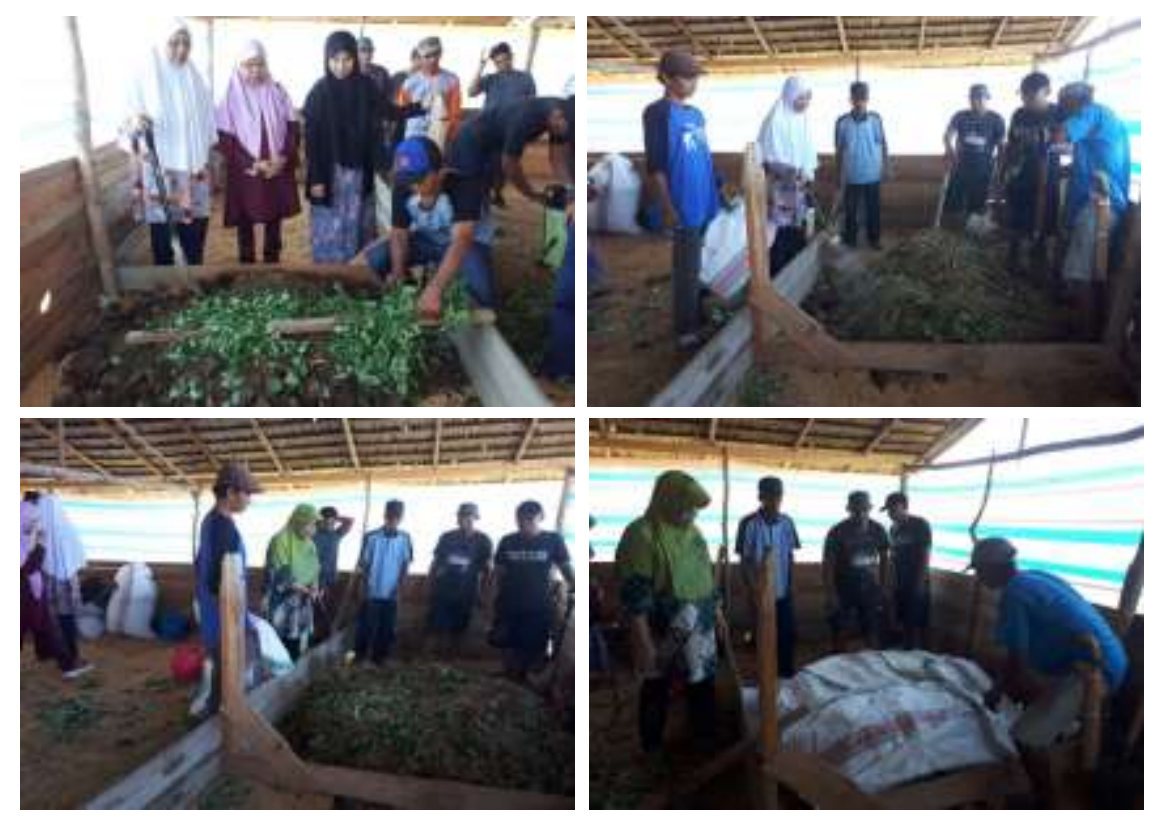

Gambar 3. Dokumentasi pelatihan pembuatan pupuk kompos

\section{Penanaman hijauan untuk pakan ternak}

Rumput pakan yang ditanam adalah rumput Panicum sarmentosum. Jenis P. sarmentozum dapat tumbuh dengan mudah, baik pada lahan subur maupun pada lahan kering. Penanaman hijauan P. sarmentozum dimaksudkan sebagai sumber bibit hijauan bagi kelompok peternak, sehingga peternak yang memerlukan bibit hijauan dapat memperoleh di kebun bibit hijauan. Dengan menanam hijauan bagi peternak, diharapkan ketersediaan pakan ternak dapat terpenuhi sepanjang waktu, sehingga ternak tidak perlu dibiarkan untuk merumput sendiri, bahkan seringkali memakan tanaman yang dibudidayakan oleh petani. Hal tersebut sesuai yang dilaporkan oleh Hayati $d k k$. (2018) bahwa salah satu upaya yang dapat dilakukan untuk ketersediaan hijauan ternak adalah pengembangan kebun induk untuk hijauan pakan ternak dengan budidaya rumput $P$. sarmentosum. Rangkaian penanaman rumput hijauan seperti ditunjukkan pada Gambar 4.

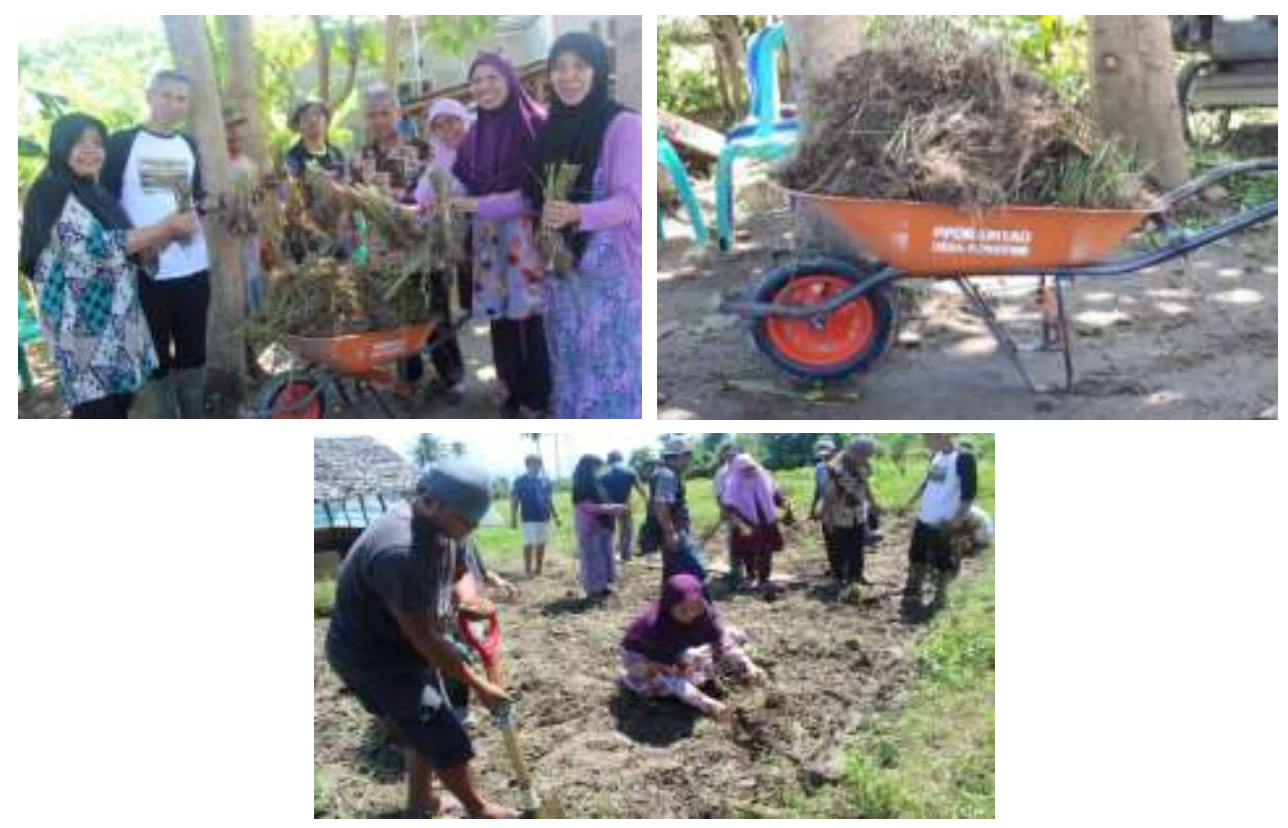

Gambar 4. Dokumentasi penanaman hijauan ternak 
Rangkaian kegiatan yang dimulai dari pembuatan pupuk organik cair MOL, pupuk kompos kotoran ternak sapi dan penanaman hijaun untuk pakan ternak yang dilaksanakan melalui program desa mitra, tidak lain adalah dalam rangka melatih masyarakat untuk memanfaatkan sumberdaya lokal yang tersedia di sekitar mereka. Limbah pertanian dan peternakan yang selama ini hanya terbuang dan bahkan menjadi salah satu sumber pencemaran lingkungan dapat dimanfaatkan melalui teknologi tepat guna dengan mengolah menjadi pupuk organik dan pestisida organik. Pupuk organik dan pestisida organik kemudian dimanfaatkan kembali dalam kegiatan usaha tani, terutama dalam usaha tani organik (Lasmini $d k k$., 2019). Siklus model pertanian tersebut dikenal dengan zero waste agriculture atau yang lebih populer disebut dengan pertanian tanpa limbah.

\section{KESIMPULAN}

Kegiatan pengabdian kepada masyarakat yang telah dilakukan memberikan banyak manfaat kepada petani seperti:

1. Peningkatan pengetahuan dan pemahaman petani di dalam pembuatan pupuk organik cair mikroorganime lokal (MOL), pupuk kompos, pestisida nabati dan budidaya pakan hijauan rumput Panicum sarmentozum.

2. Limbah pertanian dan peternakan yang sering menjadi sumber pencemaran lingkungan di sekitar permukiman warga sudah dimanfaatkan menjadi saprodi pertanian, sehingga usahatani yang dikembangkan menjadi usahatani tanpa limbah (zero waste agriculture).

3. Dengan meningkatkanya ketrampilan masyarakat maka kebutuhan pupuk dalam kegiatan usaha tani dapat dipenuhi karena masyarakat dapat mengembangkan secara sederhana dengan menggunakan potensi sumberdaya yang ada di tengah-tengah masyarakat.

\section{UCAPAN TERIMA KASIH}

Penulis menyampaikan terima kasih kepada Deputi Bidang Penguatan Riset dan Pengembangan, Kementerian Riset dan Teknologi / Badan Riset dan Inovasi Nasional yang telah memberikan dana pelaksanaan program pengabdian desa mitra, sesuai dengan Perjanjian Penugasan Pelaksanaan Program Pengabdian Masyarakat Nomor : 091/SP2H/PPM/DRPM/2020, tanggal 16 Maret 2020.

\section{DAFTAR PUSTAKA}

Bande, L.O.S., Khaerani, A.R, Saefuddin, Haetami, A., Alwi, L., Mariadi, \& Satrah, V.N. (2020). Pelatihan pembuatan pupuk hayati, agens hayati dan pestisida nabati Desa Aunupe Kabupaten Konawe Selatan. Dinamisia, 4(1), 195-200. https://doi.org/10.31849/dinamisia.v4i1.3512

BPS Kabupaten Sigi (2017). Kecamatan Sigi Biromaru dalam angka 2017. Badan Pusat Statistik Kabupaten Sigi

Haq, A. S., Nugroho, W. A., \& Lutfi, M. (2014). Pengaruh Perbedaan Sudut Rak Segitiga pada Pengomposan Sludge Biogas terhadap Sifat Fisik dan Kimia Kompos. Jurnal Keteknikan Pertanian Tropis dan Biosistem, 2(3), 225-233.

Hayati, N., Najamudin, Sulaeman \& Lasmini, S.A. (2018). Program Kemitraan wilayah dalam mengembangkan potensi sumber daya pertanian berbasis teknologi pertanian terpadu di Kabupaten Buol. Agrokreatif 4(2), 174-80. https://doi.org/10.29244/agrokreatif.4.2.174180

Kartasapoetra, A.G. (1994). Teknologi penyuluhan pertanian. Jakarta. Penerbit PT Bumi Aksara 
Kurniawati, D. (2018) Antusiasme petani membuat mikroorganisme lokal (MOL) dari Limbah buah-buahan. http://dishutbun.jogjaprov.go.id/arsip/pilihberita/492

Lasmini, S.A., Idham, Monde, A. \& Tarsono. (2019). Pelatihan Pembuatan dan pengembangan pupuk organik cair biokultur dan biourin untuk mendukung sistem budidaya sayuran. PengabdianMu, 4(2), 99-104.

Manullang, R. R., \& Daryono, R. (2017). Kombinasi mikroorganisme lokal sebagai bioaktivator kompos. Jurnal Hutan Tropis, 5(3), 259-266.

Nalhadi, A., Fatah, A., Serang, U., Raya, S., \& Serang, U. (2020). Pemberdayaan masyarakat dalam pemanfaatan limbah rumah tangga menjadi pupuk organik cair. Wikrama Parahita, 4(1), 4346. https://doi.org/http://dx.doi.org/10.30656/jpmwp.v4i1.213

Nurazizah, S. (2019). Cara membuat mol dari limbah buah-buahan. http://cybex.pertanian.go.id/mobile/artikel/76275/Cara-Membuat-Mol-Dari-Limbah-Buahbuahan

Pasandaran, E., Djajanegara, A., Kariyasa, K. \& Kasryno, F. (2006). Kerangka Konseptual integrasi tanaman-ternak di Indonesia. Dalam integrasi tanaman-ternak di Indonesia. Badan Penelitian dan Pengembangan Pertanian, Departemen Pertanian. hlm. 11-31

Sabiham, S. (2008). Manajemen Sumberdaya lahan dan usaha pertanian berkelanjutan. Dalam Arsyad, S. \&. Rustiadi, E. (Ed), Penyelamatan tanah, air dan lingkungan. Crestpent Press dan Yayasan Obor Indonesia. 3-16

Salikin, K.A. (2003). Sistem pertanian berkelanjutan. Yogyakarta; Kanisius

Setyorini, D., Saraswati, R. \& Anwar. E.K. Kompos. http://balittanah.litbang.pertanian.go.id/ind/dokumentasi/lainnya/02kompos.pdf 